\title{
Arrests reveal debate about costs and benefits of proton therapy
}

In the US, radio advertisements tout the benefits of proton radiation therapy for prostate cancer. But when the parents of a five-year-old patient with cancer, Ashya King, left the UK to seek this treatment abroad a month ago, they were arrested by Spanish police for seeking the pricey therapy against the recommendations of the boy's UK doctors. The family was ultimately reunited and allowed to travel to Prague for the controversial treatment, which is not available in the UK, aside from a low-energy version used to treat eye tumors. However, the ordeal has thrust proton-beam therapy back into the spotlight and reignited the debate over how cost effective it is for various cancers.

The technology, which has been around since the 1950s, was approved by the US Food and Drug Administration (FDA) in 1988 and has come into routine use for cancers such as pediatric brain tumors in only the last two decades. Today, there are 15 proton therapy centers in operation in the US and 28 others throughout the world. The total number will nearly double when centers in planning and construction stages are completed. But the high construction and operating costs of these centers and the limited data demonstrating that proton therapy is superior to the current standard of care for many cancers have made it controversial. The centers cost \$100-250 million to build-about 40 times the cost of setting up a state-of-the-art photon radiation center, which makes use of much smaller particles called electrons.

By 2018, the UK's National Health Service (NHS) plans to open proton therapy centers at the University College London Hospital and the Christie NHS Foundation Trust in Manchester. To do so, it is investing $£ 250$ million (\$406 million) in these two centers, which will treat a combined 1,500 patients per year. The UK's Department of Health determined this

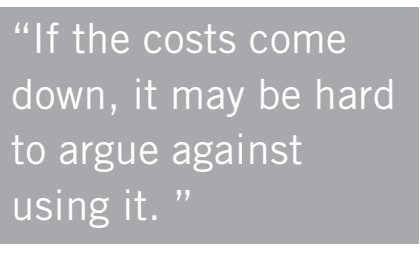

president for clinical oncology of the Royal College of Radiologists in London.

Ashya King's tumor, medulloblastoma, is not on the Panel's list, Taylor explains, because treatment success requires immediate radiation. The time it takes to arrange treatment and travel abroad "would compromise what is currently a good chance of cure," he says. It's unclear whether the criteria will change after the UK centers are built. The UK National Cancer Research Institute's Clinical and Translational Radiotherapy Research Working Group met in June to discuss a research plan, stating in a summary of the meeting that "the priority is to focus on what can be achieved with protons that cannot be done with other types of radiotherapy."

\section{Heavy matters}

Both proton and standard photon radiation achieve the same goal of damaging tumor cell DNA. But because protons are heavier, they stop at their target, thus reducing extra radiation to noncancerous areas. This is ideal for treating tumors near sensitive structures, such as the brain or spinal cord, or for treating childhood cancers, as radiotherapy comes with a risk of developing secondary cancers decades later. In June, the American Society for Radiation Oncology (ASTRO) released a model policy supporting the use of proton therapy for a select list of cancers, including tumors at the base of the skull or near the spine and pediatric tumors. For others, such as lung and prostate cancers, ASTRO recommends patients receive proton treatment only within a clinical trial setting because it remains unclear how much advantage it offers over other therapies.

Proton therapy for prostate cancer is often cited as a simple highthroughput treatment that large centers perform to recoup their costs (J. Am. Coll. Radiol. 9, 560-563, 2012). By comparison, pediatric patients take longer to treat because they often was more cost effective than the current system of sending patients abroad for treatment. Currently, the NHS covers travel expenses and treatment for patients deemed eligible by the England Proton Overseas Program National Clinical Reference Panel. "This is a success, really, in the way we've been able to get access to centers abroad," says Roger Taylor, the vice need anesthesia, and base of skull and spinal tumors are rare. Retrospective and singlearm studies have yielded conflicting results regarding proton therapy's advantages in prostate cancer (Rev. Urol. 16, 67-75, 2014). "Proton beam therapy is effective for prostate cancer patients. Is it better than [photons]? I don't think we can say that," says Bruce Haffty,

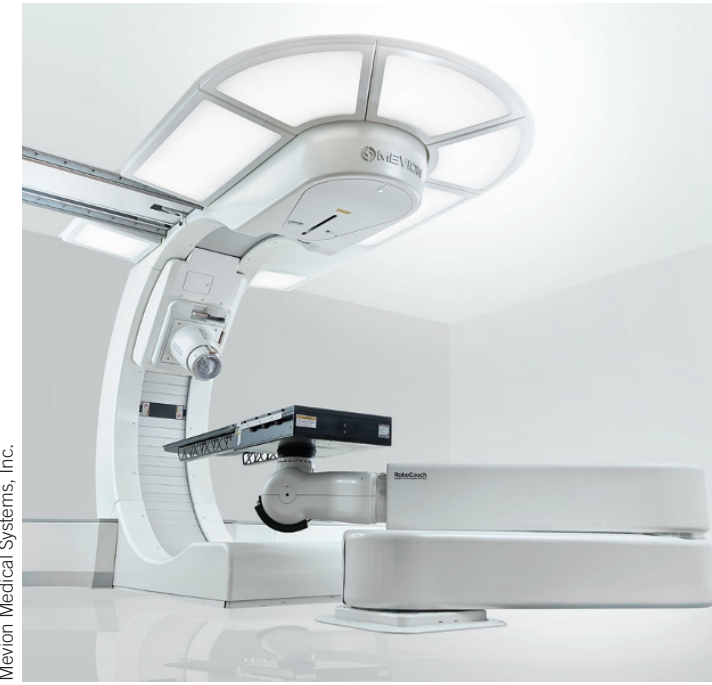

On the table: proton therapy facilities.

a radiation oncologist at Rutgers University's Robert Wood Johnson Medical School in New Brunswick, New Jersey, and former president of ASTRO. "We have to encourage continued research," he says. The first randomized controlled study is currently underway at centers in Boston and Philadelphia.

Large-scale randomized trials have been difficult to conduct because of the low number of proton centers. "The biggest problem in proton therapy today is there are only 15 centers where you could get it" in the US, says Steven Frank, a radiation oncologist at the University of Texas MD Anderson Cancer Center in Houston. Frank says that if everyone had affordable access to the therapy, there would be no question about using it for all types of tumors because it minimizes unnecessary radiation. "If the costs come down, it may be hard to argue against using it," he says.

There are some signs the cost may come down. Two companies, Mevion Medical Systems and Ion Beam Applications, are installing smaller \$25 million devices within existing cancer centers. David Mansur, a pediatric radiation oncologist, says his hospital, University Hospitals Case Medical Center in Cleveland, Ohio, which is sixth in line to install a Mevion system, will reserve it for treatments recommended by the ASTRO model policy. "When you're talking about something that's a limited resource, you have to exercise some patient selection," he says. "Let's keep our eye on the ball-let's save it for people who need it the most."

Amanda B Keener 